\title{
Remote Sensing Monitoring of Volcanic Ash Clouds Based on PCA Method
}

\author{
Chengfan LI, Yangyang DAI, Junjuan ZHAO, Shiqiang ZHOU, \\ Jingyuan YIN, and Dan XUE
}

School of Computer Engineering and Science, Shanghai University, Shanghai, China; e-mail: david-0904@163.com (corresponding author)

\begin{abstract}
Volcanic ash clouds threaten the aviation safety and cause global environmental effects. It is possible to effectively monitor the volcanic ash cloud with the aid of thermal infrared remote sensing technology. Principal component analysis (PCA) is able to remove the inter-band correlation and eliminate the data redundancy of remote sensing data. Taking the Eyjafjallajokull volcanic ash clouds formed on 15 and 19 April 2010 as an example, in this paper, the PCA method is used to monitor the volcanic ash cloud based on MODIS bands selection; the USGS standard spectral database and the volcanic absorbing aerosol index (AAI) are applied as contrasts to the monitoring result. The results indicate that: the PCA method is much simpler; its spectral matching rates reach 74.65 and $76.35 \%$, respectively; and the PCA method has higher consistency with volcanic AAI distribution.
\end{abstract}

Key words: remote sensing, principal component analysis (PCA), volcanic ash cloud, monitoring, aviation safety.

\section{INTRODUCTION}

The volcanic ash cloud, formed by the volcanic eruption, is usually consisted of pyroclastic particles, water vapor, $\mathrm{SO}_{2}$ and $\mathrm{HCL}$, etc. These components can be combined to form acidic aerosols when they erupt into the atmosphere troposphere, and cause global environmental problems (Wen and Rose 1994, Flynn et al. 2001, Ellrod 2004, Thomas et al. 2005, Andronico et al. 2009, Mastin et al. 2009, Webley and Mastin 2009). Currently, the civil air-

Ownership: Institute of Geophysics, Polish Academy of Sciences;

(C) $2015 \mathrm{Li}$ et al. This is an open access article distributed under the Creative Commons

Attribution-NonCommercial-NoDerivs license,

http://creativecommons.org/licenses/by-nc-nd/3.0/. 
crafts' flight height is mostly $6-15 \mathrm{~km}$ and basically belongs to the troposphere. Once a large number of volcanic ash clouds appear in the stratosphere layer, it will easily cause aviation security risks. Remote sensing can obtain the real-time information of volcanic ash cloud. Thereinto, the infrared remote sensing has been rapidly developed since the infrared light was discovered in the year 1800. At present, there are several thermal infrared satellite remote sensing sensors which have been widely used in the field of air pollution, sea surface brightness temperature and volcanic activity monitoring (Qin et al. 2001, Jiménez-Muñoz and Sobrino 2003, Liu et al. 2003, Qu et al. 2006, Yao et al. 2007, Krueger 1983, McCarthy et al. 2008, Filizzola et al. 2007, Rose et al. 2008). In view of the significant impact of massive volcanic ash cloud on the global environment and aviation safety, how to detect volcanic ash cloud from remote sensing data has become one of the most important tasks in the volcanoes and security realms.

Principal component analysis (PCA) is an effective mathematical method whose aim is to transform multiple indicators into a few composite indicators using dimensionality reduction. It has been widely adopted in data compression, feature extraction and pattern identification fields (Hillger and Clark 2002a, b, Hillger and Ellrod 2003). The monitoring of volcanic ash cloud produced by the large-scale volcanic eruptions has been carried out since the 1980s. Zhu et al. (2011) have used FY-3A remote sensing data to present shortwave infrared-thermal infrared volcanic ash (STVA) method, and have achieved a higher detecting precision. Hillger and Clark (2002a, b) have processed the moderate resolution imaging spectroradiometer (MODIS) data of Popocatepetl and Cleveland volcanic ash clouds with the PCA method, and have accurately identified the volcanic ash cloud distribution in the lower atmosphere. The essence of volcanic ash cloud monitoring is also a pattern recognition problem, and along with a certain relevance and data redundancy coming from each band of remote sensing data, although the PCA method has great application potential, there are relatively fewer studies on the volcanic ash cloud monitoring using PCA method, and the research achievements are few.

According to the physical-chemical properties of volcanic ash cloud, taking the MODIS data of Eyjafjallajokull volcanic ash clouds on 15 and 19 April 2010 as the data source, this paper uses the PCA method to detect volcanic ash cloud with the aim to provide a reference for other volcanic ash cloud monitoring researches. Section 1 introduces the general situation and research status of volcanic ash cloud, Section 2 describes PCA basic principles and its realization process in remote sensing image, Section 3 is the detailed detection process of volcanic ash cloud from MODIS images using PCA method, Section 4 gives detection results, and Section 5 presents the conclusions and discussions. 


\section{THEORETICAL BASIS}

PCA method is a kind of dimensionality reduction method whose assumption is that a given set of relevant variables is converted into another group of irrelevant variables by linear transformation, and these new variables are ordered sequentially in accordance with the variance in descending order (Lin et al. 2012, Zhao et al. 2012).

\subsection{PCA principles}

Suppose $x$ is $m$-dimensional random vector, and the $E[x]=0$, the realization process of PCA is shown below.

Step 1. Calculate: $Q=\left[x_{1}-x, x_{2}-x, \ldots, x_{m}-x\right]_{n \times m}$, in which $x=\frac{1}{m} \sum_{j=1}^{m} x_{j}$, and then calculate matrix $R=Q^{T} Q$ according to $Q$.

Step 2. Calculate $s$ maximum eigenvalues $\lambda_{1} \geq \lambda_{2} \geq \ldots \geq \lambda_{s}$ and corresponding orthogonal eignvectors $v_{1}, v_{2}, \ldots, v_{s}$ of $R$.

Step 3. Calculate the eigenvectors $w_{1}, w_{2}, \ldots, w_{s}$ of covariance matrix $\mathrm{C}=Q Q^{T} / m$. Hereinto, $w_{d}=Q v_{d} / \sqrt{\lambda_{d}}, d=1,2, \ldots, s$, and $W=\left[w_{1}, w_{2}, \ldots, w_{s}\right]$. Step 4. Calculate the feature $Y=\left[y_{1}, y_{2}, \ldots, y_{m}\right]$ of $x$, where $y_{p}=W^{T} x_{p}$, $p=1,2, \ldots, m$.

\subsection{PCA realization process in remote sensing image}

According to PCA principles, the first principal component (PC 1) is required to have the largest possible variance, the second principal component (PC 2) is computed under the constraint that it is orthogonal to PC 1, and so forth (Lin et al. 2012). Next, this study takes the multispectral remote sensing images with $N$ bands as an example, and then describes the realization process of PCA method in multispectral remote sensing images. Hereinto, the PCs obtained from remote sensing images using PCA method are called principal component images (PCIs) (Hillger and Clark 2002a, b, Li et al. 2011).

Let $E$ be the transformation matrix, and $B$ the multispectral remote sensing image with $N$ bands, so the relationship between PCIs and the multispectral remote sensing images can be explained as follows:

$$
\mathrm{PCI}=E \cdot B=E \cdot\left[\begin{array}{cccc}
b_{11} & b_{12} & \ldots & b_{1 m} \\
b_{21} & b_{22} & \ldots & b_{2 m} \\
\ldots & \ldots & \ldots & \ldots \\
b_{n 1} & b_{n 2} & \ldots & b_{n m}
\end{array}\right]=E \cdot\left[\begin{array}{c}
B_{1} \\
B_{2} \\
\ldots \\
B_{n}
\end{array}\right]
$$

and, furthermore, we can rewrite the PCI as follows: 


$$
\left\{\begin{array}{c}
\mathrm{PCI}_{1}=e_{1} B=e_{11} B_{1}+e_{12} B_{2}+\ldots+e_{1 n} B_{n} \\
\mathrm{PCI}_{2}=e_{2} B=e_{21} B_{1}+e_{22} B_{2}+\ldots+e_{2 n} B_{n} \\
\ldots \ldots \ldots \ldots \ldots \ldots \ldots \ldots \ldots \ldots \ldots \ldots \ldots \ldots \ldots \ldots \ldots \ldots \ldots \ldots \ldots \\
\mathrm{PCI}_{n}=e_{n} B=e_{n 1} B_{1}+e_{n 2} B_{2}+\ldots+e_{n n} B_{n}
\end{array} .\right.
$$

Similarly, the first principal component image (PCI 1) has the maximum variance and contains the maximum commonalities of each multispectral remote sensing image. Other PCIs often lay emphasis on the difference among the original remote sensing images, and this difference in a single original image is invisible. Besides, the noise (also called blemishes) appears primarily in the $n$-th principal component image ( $\mathrm{PCI} n$ ).

\section{REMOTE SENSING MONITORING OF VOLCANIC ASH CLOUD}

\subsection{General situation of study area}

Iceland is located east of Greenland and immediately south of the Arctic Circle. Although its area is only $103000 \mathrm{~km}^{2}$, it is known as the Fire Island of Polar Circle. The Eyjafjallajokull volcano is located to the southeast of the Reykjavik, and began to erupt in the evening on 20 March 2010. Subsequently, the Eyjafjallajokull volcano erupted violently again on 14 April 2010. The volcanic ash cloud spread to Continental Europe and North Atlantic by wind, causing most European airports to be closed; more than 1000 flights were canceled, and the direct financial loss amounted to about hundreds of billions of euros. According to the relevant documentation and meteorological conditions, the MODIS images on 15 and 19 April 2010 are eventually used in this study in the monitoring of the volcanic ash cloud (Fig. 1).

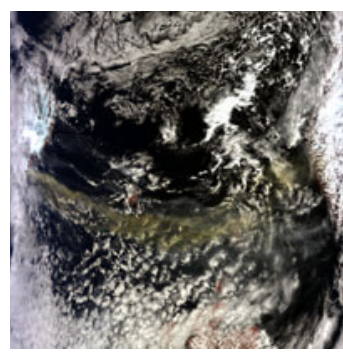

(a)

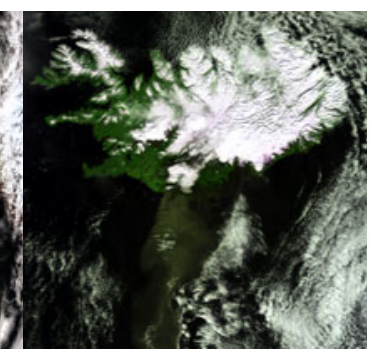

(b)

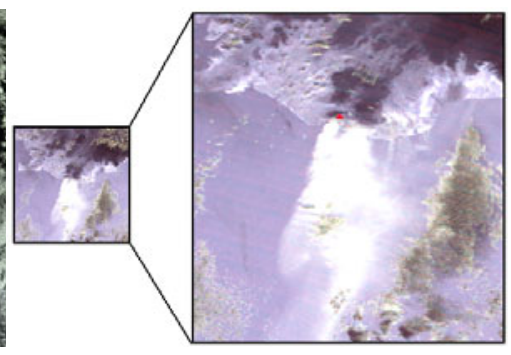

(c)

Fig. 1: (a) MODIS image of Eyjafjallajokull volcanic ash cloud on 15 April 2010, (b) MODIS image of Eyjafjallajokull volcanic ash cloud on 19 April 2010, and (c) enlarged Eyjafjallajokull volcanic ash cloud, in which the red point is the Eyjafjallajokull caldera. 
Figures 1a and $\mathrm{b}$ show the false color composite image of MODIS data band 2, 1, 3 acquired on 15 and 19 April 2010, respectively; the corresponding center wavelengths of three corresponding bands are $0.859,0.645$, and $0.469 \mu \mathrm{m}$. From Figs. 1a and $\mathrm{b}$ it is seen that the color of volcanic ash cloud is close to the one of the sea and land surface, so it is difficult to distinguish the volcanic ash cloud; it depends entirely on visual inspection. Figure 1c shows an enlarged image of the volcanic ash cloud and the volcanic caldera acquired from MODIS thermal infrared remote sensing images. As can be seen from Figs. 1a and c, when the volcanic ash cloud rushes upward and spreads southward and eastward by wind, the volcanic ash cloud components become thinner and spread out of the caldera's periphery. However, the spreading volcanic ash cloud does not cover the volcanic caldera and the caldera is clear in Fig. 1c.

\subsection{PCA on the MODIS thermal infrared bands}

Due to the method of PCA processing and effective spectral bands selection with MODIS, the thermal infrared bands on 15 and 19 April 2010 are the same; this paper just takes the case of the volcanic ash cloud on 19 April 2010. The MODIS sensor is an important remote sensor mounted in the Terra and Aqua satellites whose data can be freely received and used by worldwide users. MODIS sensor has a total of 36 discrete spectral bands, the spectral range covers the bands from visible to thermal infrared; its spatial resolutions are 250,500 , and $1000 \mathrm{~m}$, respectively, and the maximum scan width is $2330 \mathrm{~km}$. Spectral sensitivity is the relative efficiency of the signal as a function of the frequency of the signal; signal to noise ratio (SNR) is a measure that compares the level of a desired signal to the level of background noise. Both are an indication of the relative magnitude of the signal in these bands of the MODIS sensor, and are often used to evaluate its performance (Table 1).

In recent years, many researchers have been exploring the monitoring methods of volcanic ash cloud using different thermal infrared remote sensors, especially the advanced, very high resolution radiometer (AVHRR) remote sensor. Because the MODIS sensor is an updated product of AVHRR, how to reasonably use MODIS data to obtain volcanic ash cloud should be considered in the future study. In order to verify the thermal infrared band's sensitivity for the volcanic ash cloud in MODIS data (bands 20-36, except of band 26), this study adopts PCA method to process the MODIS thermal infrared bands. According to PCA principle, when the 16 thermal infrared bands are inputted, the corresponding 16 separated PCIs are obtained. The PCIs on 19 April 2010 are shown in Fig. 2.

Generally speaking, the principal component information in PCIs is also called explained variance. The PCI 1 has the biggest principal component in- 
Table 1

The MODIS thermal infrared bands distribution and performance

\begin{tabular}{|c|c|c|c|c|}
\hline Bands & $\begin{array}{c}\text { Resolution } \\
{[\mathrm{m}]}\end{array}$ & $\begin{array}{c}\text { Band width } \\
{[\mu \mathrm{m}]}\end{array}$ & $\begin{array}{c}\text { Spectral sensitivity } \\
{\left[\mathrm{W} / \mathrm{m}^{2} \cdot \mu \mathrm{m} \cdot \mathrm{sr}\right]}\end{array}$ & $\begin{array}{c}\text { SNR } \\
{[\mathrm{k}]}\end{array}$ \\
\hline 20 & 1000 & $3.660-3.840$ & 0.45 & 0.05 \\
21 & 1000 & $3.929-3.989$ & 2.38 & 2.00 \\
22 & 1000 & $3.929-3.989$ & 0.67 & 0.07 \\
23 & 1000 & $4.020-4.080$ & 0.79 & 0.07 \\
24 & 1000 & $4.433-4.498$ & 0.17 & 0.25 \\
25 & 1000 & $4.482-4.549$ & 0.59 & 0.25 \\
27 & 1000 & $6.535-6.895$ & 1.16 & 0.25 \\
28 & 1000 & $7.175-7.475$ & 2.18 & 0.25 \\
29 & 1000 & $8.400-8.700$ & 9.58 & 0.05 \\
30 & 1000 & $9.580-9.880$ & 3.69 & 0.25 \\
31 & 1000 & $10.780-11.280$ & 9.55 & 0.05 \\
32 & 1000 & $11.770-12.270$ & 8.94 & 0.05 \\
33 & 1000 & $13.185-13.485$ & 4.52 & 0.25 \\
34 & 1000 & $13.485-13.785$ & 3.76 & 0.25 \\
35 & 1000 & $13.785-14.085$ & 3.11 & 0.25 \\
36 & 1000 & $13.085-14.385$ & 2.08 & 0.35 \\
\hline
\end{tabular}

formation of the original remote sensing images. As can been seen from Fig. 2, PCI 1 contains the vast majority of components' information. In this study, the image background mainly includes meteorological clouds and land cover information:

a For a meteorological cloud, the higher the meteorological cloud, the brighter the color. This is due to the different absorbed heat caused by varying height of the meteorological cloud. When the cloud is higher, its brightness temperature in the range of thermal infrared band will be lower and the color will be brighter due to the absorption of smaller amount of the earth radiation heat. When the cloud is lower, on the contrary, its brightness temperature is higher and the color is darker because of the absorption of much of the earth radiation heat;

- For land cover information, the gray color of light means low brightness temperature and black means high brightness temperature; the gray color represents gradual changes of the brightness temperature between light gray and black. In PCIs, its color gradually changes from light gray to black; this indicates that the surface brightness temperature of land cover information changes from low to high. 


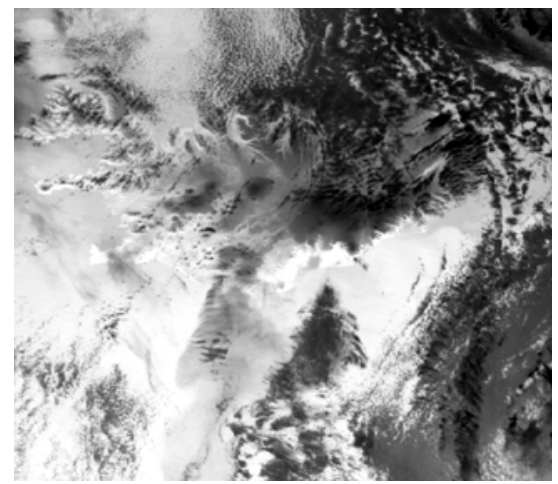

(a)

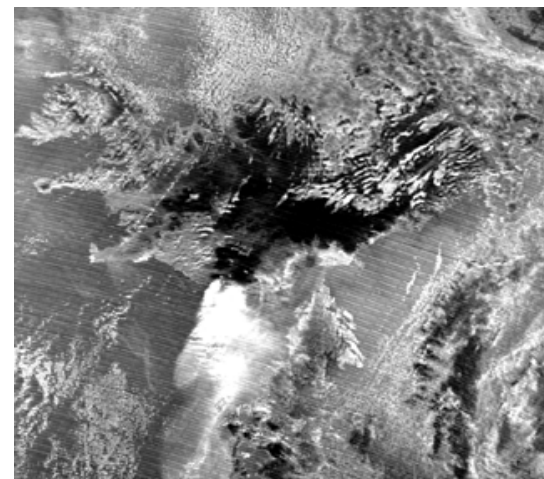

(c)

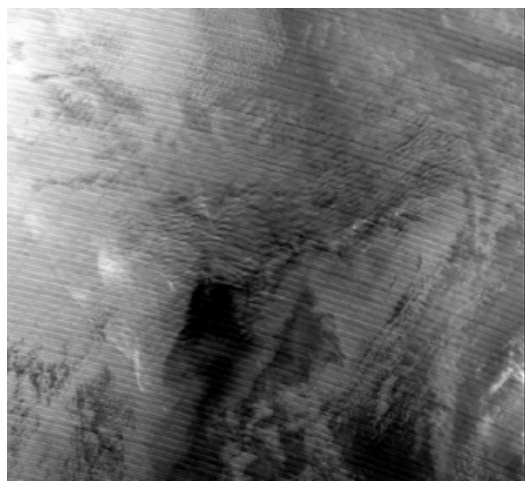

(b)

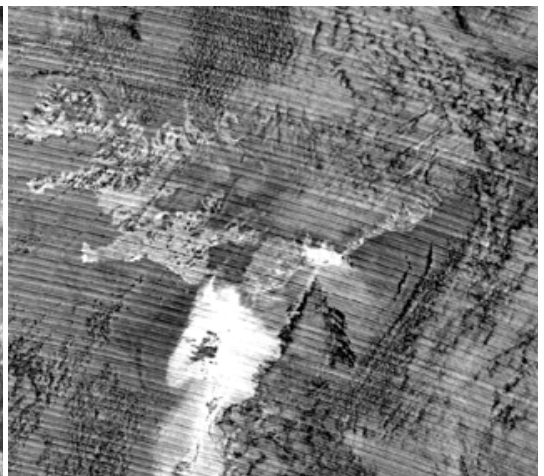

(d)

Fig. 2. PCIs of MODIS thermal infrared band acquired on 19 April 2010; (a), (b), (c), and (d) are PCI 1, 2, 4, and 8 images, respectively, other PCIs are basically noise information and are omitted.

For the obtained PCIs, the volcanic ash cloud information is detected clearly only in PCI 1, 2, 4, and 8; as other PCIs are basically full of noise, they are all ignored in the study (Fig. 2). In addition, from the viewpoint of a contrast between volcanic ash cloud and background feature, PCI 4 is clear with significant contrast in all PCIs, it is followed by PCI 1 and 8; and PCI 2 has less contrast. Even so, the distributions of volcanic ash cloud information are basically detected in the four PCIs.

\subsection{Selection of effective spectral bands}

In order to give a quantitative analysis of the detected volcanic ash cloud using PCI 1, 2, 4, and 8, the explained variance and SNR of different PCIs are calculated. According to the principle of diminishing amount, the PCIs contrasts of volcanic ash cloud are shown in Table 2 . 
Table 2

PCIs contrasts of volcanic ash cloud

\begin{tabular}{|c|l|c|c|}
\hline PCI & \multicolumn{1}{|c|}{ Contrast effect } & $\begin{array}{c}\text { Explained variance } \\
{[\%]}\end{array}$ & SNR \\
\hline 4 & Good ash signal & 0.13 & 1.66 \\
1 & Good ash signal, but cloud contamination & 0.20 & 1.33 \\
8 & Good ash signal, noisy & 0.008 & 4.55 \\
2 & Densest ash only, low contrast & 0.011 & 1.58 \\
\hline
\end{tabular}

As can be seen from Table 2, the volcanic ash cloud information in the PCI 4 is that the cloud is obviously bright and has the biggest contrast to the image background and the best detection effect. The following one is PCI 8; although the contrast decreases and is between the volcanic ash cloud and the image background, the volcanic ash cloud can still be clearly detected; the volcanic ash cloud showing dark tones in PCI 1, the cloud shows bright tones, the land shows darker tones; the volcanic ash cloud shows dark tones in PCI 2, and the other features are basically in light tones. In addition, from the view of explained variance and SNR, the explained variance and SNR of PCI 4 have the best contrast effect, and reach 0.13 and 1.66, respectively, the explained variance and SNR of PCI 2 have the least obvious contrast effect, and reach 0.011 and 1.58 , respectively. Thus, it has not been confirmed that the greater the explained variance and SNR value, the better the volcanic ash cloud contrast effect.

Table 3 shows the contributions from MODIS bands to PCI with a better volcanic ash cloud detection effect. For PCI 4, the contribution rate of band 30 is the largest, it is followed by band 36; for PCI 1, the contribution rate of band 36 is the largest, followed by band 25; for PCI 8 , the contribution rate of bands 31 and 32 are the largest, respectively, the contribution rate of other bands is relatively smaller; for PCI 2, the contribution rate of bands 29 and 32 are the largest. Taken together, for

Table 3

Contributions from MODIS bands to PCIs [\%]

\begin{tabular}{|c|r|r|r|r|r|r|r|r|r|}
\hline PCI & 20 & 25 & 29 & 30 & 31 & 32 & 33 & 34 & 36 \\
\hline 4 & 2 & 9 & 0 & 52 & 0 & 0 & 1 & 1 & 17 \\
1 & 3 & 13 & 3 & 10 & 2 & 0 & 2 & 5 & 55 \\
8 & 1 & 0 & 6 & 0 & 64 & 11 & 1 & 0 & 0 \\
2 & 0 & 0 & 32 & 3 & 1 & 26 & 0 & 0 & 0 \\
\hline Total & 6 & 22 & 41 & 65 & 67 & 37 & 4 & 6 & 72 \\
\hline
\end{tabular}


PCI 9, 8, 16, and 14, band 36 has the largest contribution to the volcanic ash cloud with the total contribution rate of $72 \%$; followed by bands 31 and 30 , respectively, whose total contribution rates reach 67 and $65 \%$.

In addition, different combinations of PCIs are also able to reveal the object feature under different circumstances. For example, PCI 9 is the essential difference between ozone band and long-wave $\mathrm{CO}_{2}$ band (corresponding to 9.7 and $14.2 \mu \mathrm{m}$ ); PCI 8 is mainly the difference between short-wave and long-wave $\mathrm{CO}_{2}$ band (corresponding to 4.52 and $14.2 \mu \mathrm{m}$ ); PCI 16 is the difference between long wave window band and nearby dirty window band (corresponding to 11.0 and $12.0 \mu \mathrm{m}$ ); PCI 14 is the difference between water vapor band and dirty window band (corresponding to 8.6 and $12.0 \mu \mathrm{m}$ ). For different application fields, we are required to select the suitable PCIs in terms of the actual situation.

\subsection{PCA on selected effective bands}

Through the above analysis, the thermal infrared bands 30,31, and 36 in MODIS have the biggest contribution to the volcanic ash cloud PCIs. Next, taking the original bands 30,31 , and 36 of MODIS sensors as the data source, this study will detect the Eyjafjallajokull volcanic ash cloud using 3band PCA method on 15 and 19 April 2010, respectively. Figure 3 shows the selected MODIS images on 15 April 2010 and the corresponding PCIs. Figure 4 shows the selected MODIS images on 19 April 2010 and the corresponding PCIs.

From Figs. 3a-c and 4a-c it is seen that some fractus clouds have lower temperature in the original band 36 and show light tones, while some other, stratiform clouds have higher equivalent black body temperature (TBB) and show gray color. This is so because the volcanic ash cloud in the early eruption period and diffusion process contains a lot of heat and its brightness temperature is higher than that of TBB, which is more conventional. The brightness temperature characteristics of volcanic ash cloud in original bands 30 and 31 are similar to that of band 36. During the day, the brightness temperature of volcanic ash cloud is higher and the concentration is greater than that of meteorological clouds; all these factors make the image appear to be in dark tones.

From Figs. 3d-f and 4d-f it follows that the distinction between the volcanic ash cloud and the image background in PCI 2 is most obvious. The volcanic ash cloud is gray and has a clearly visible edge, relatively uniform texture; it also highlights the texture and spectral characteristics of volcanic ash cloud. In stark contrast, the surrounding white scattered clouds have fragmentary and chaotic texture. Although PCI 3 contains a certain amount of noise, the volcanic ash cloud information is highlighted. Due to the carried heat and radiation heat from itself, the volcanic ash cloud's brightness 


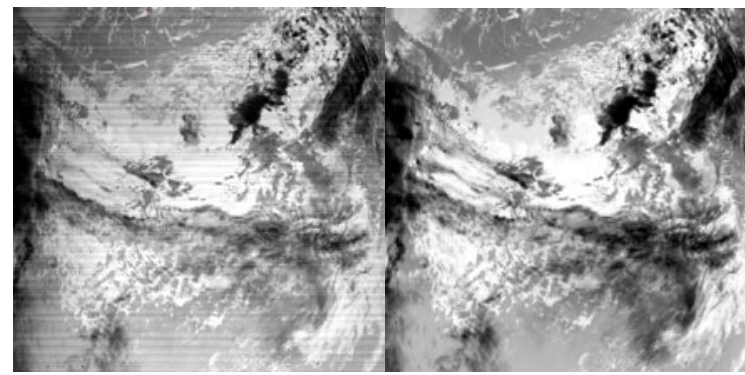

(a)

(b)

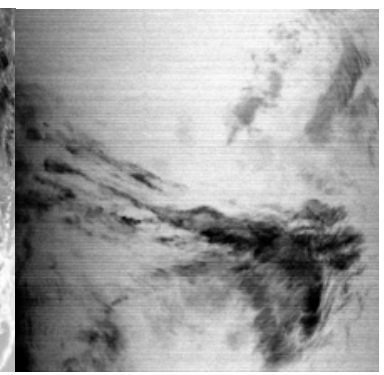

(c)

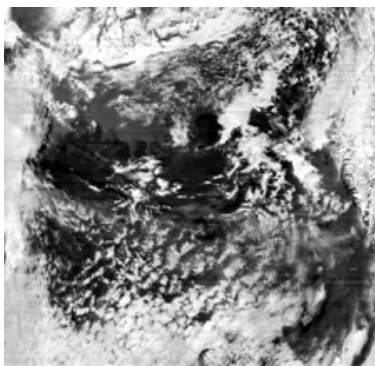

(d)

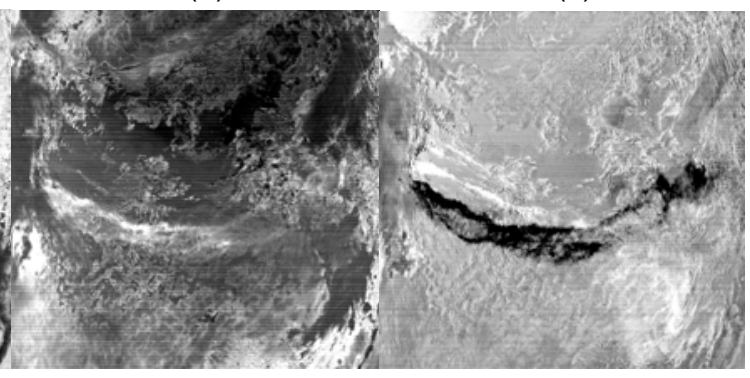

(e)

Fig. 3. The selected MODIS images and PCIs on 15 April 2010: (a)-(c) are the original bands 30, 31, and 36, respectively; (d)-(f) are PCI 1, 2, and 3, respectively.

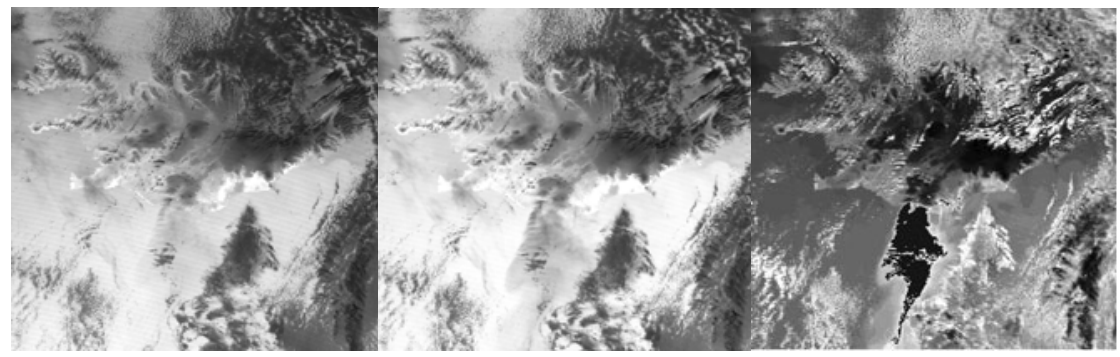

(a)

(b)

(c)

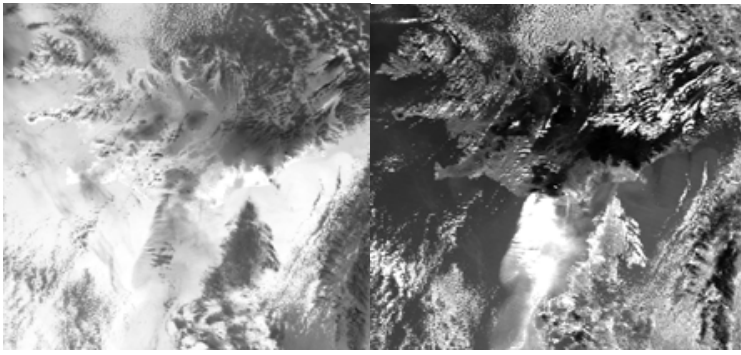

(d)

(e)

Fig. 4. The selected MODIS images and PCIs on 19 April 2010: (a)-(c) are the original bands 30, 31, and 36, respectively; (d)-(f) are PCI 1, 2, and 3, respectively. 


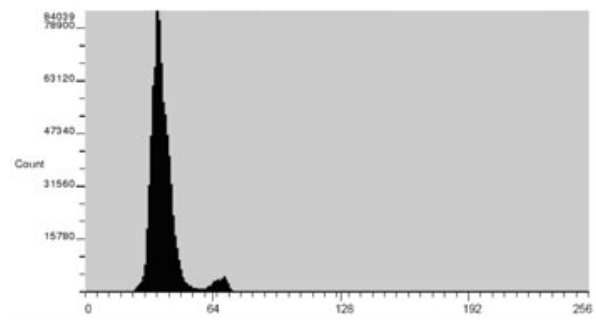

(a)

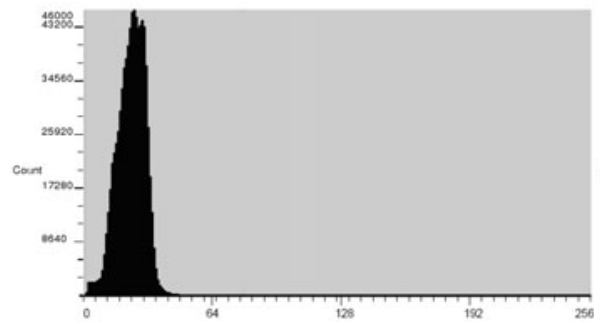

(c)

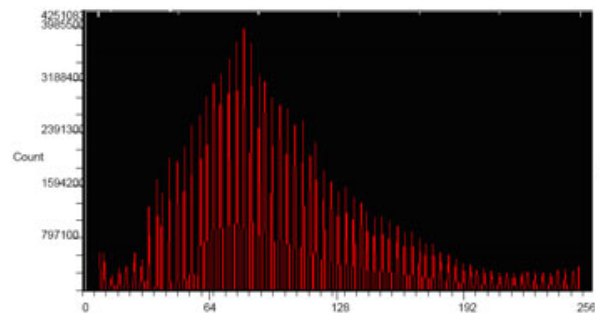

(e)

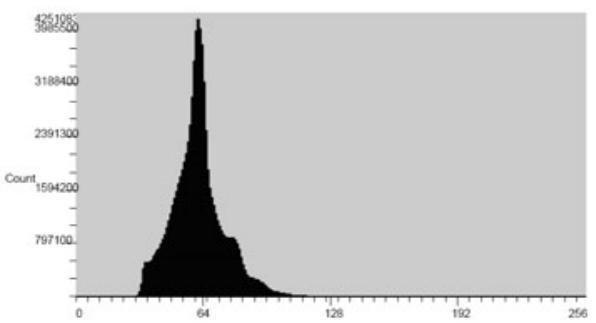

(b)

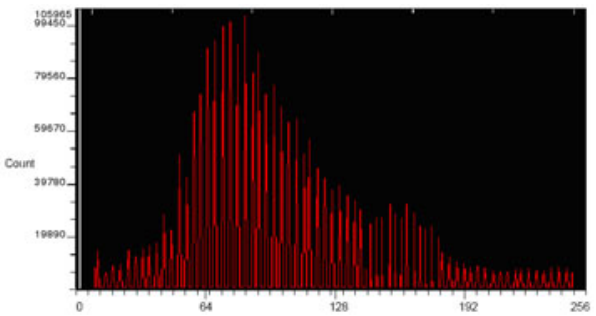

(d)

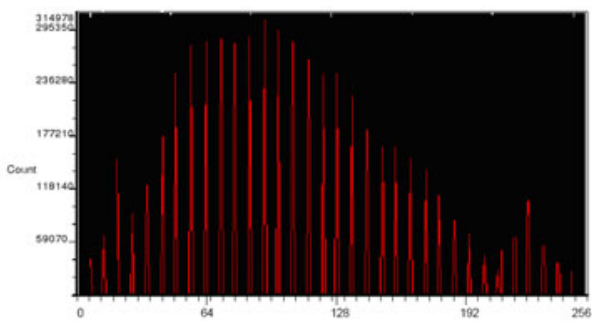

(f)

Fig. 5. The color histogram of the original bands and PCIs on 15 April 2010: (a)-(c) are the original bands 30,31 , and 36, respectively; (d)-(f) are corresponding PCI 1, 2 , and 3 , respectively.

temperature is higher than that of the surrounding land and cloud, and appears to be in dark tones.

In order to more accurately evaluate the difference between the original multispectral remote sensing image and PCIs, in this study, the color histogram of the original bands 30,31 , and 36 in MODIS and the corresponding PCI 1, 2, and 3 on 15 April 2010 (Fig. 5) and 19 April 2010 (Fig. 6) are calculated. Figures 5a-c and 6a-c show that the color histogram of the bands 30 , 31 , and 36 is very similar, and the three bands have high inter-band correlation. On the contrary, the color histogram of PCIs in the Figs. 5d-f and 6d-f is completely different and has different spatial distribution. This indicates that the PCIs by PCA processing can effectively remove the inter-band correlation among the original remote sensing images and greatly enhance the subsequent detection of volcanic ash cloud. 


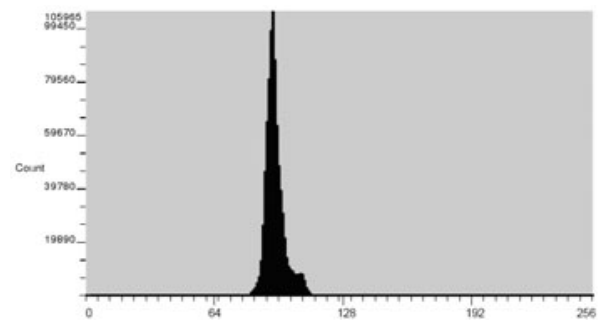

(a)

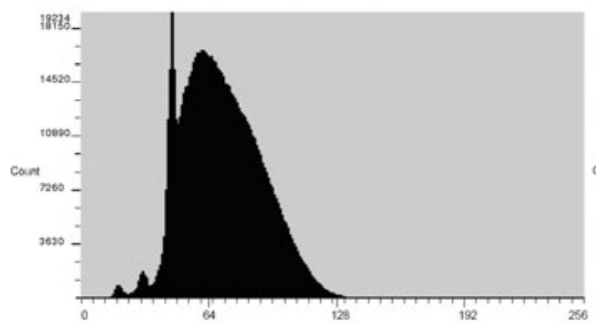

(c)

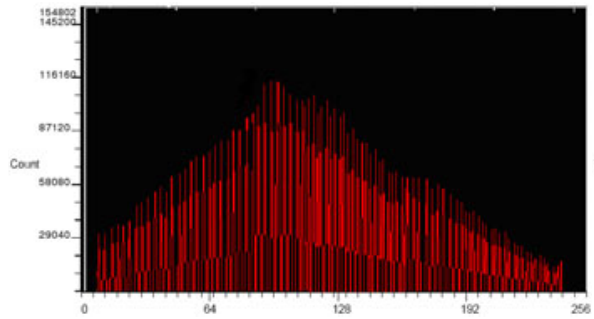

(e)

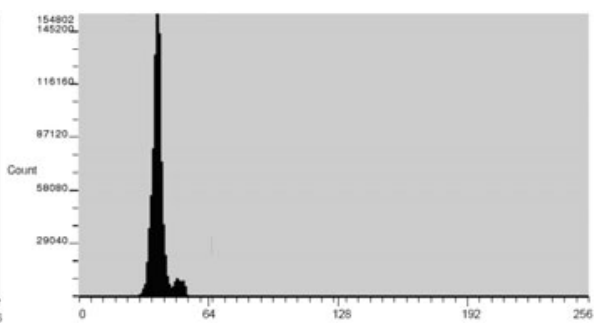

(b)

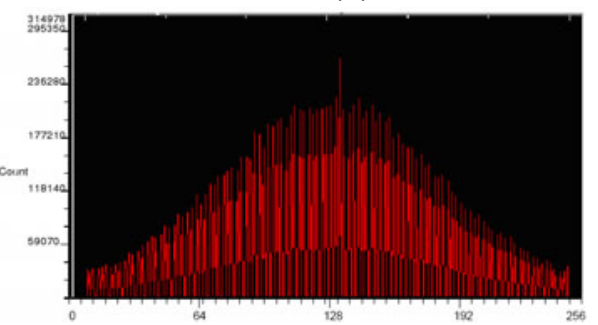

(d)

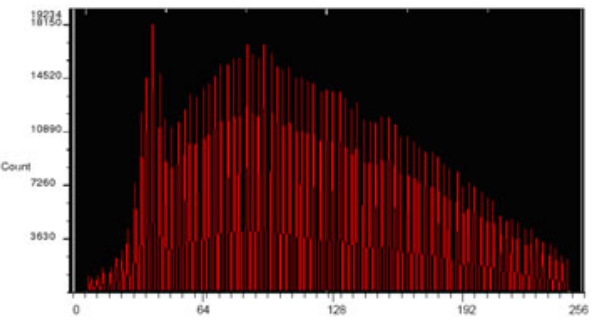

(f)

Fig. 6. The color histogram of the original bands and PCIs on 19 April 2010: (a)-(c) are the original bands 30, 31, and 36, respectively; (d)-(f) are corresponding PCI 1, 2 , and 3 , respectively.

\subsection{PCIs noise elimination and segmentation}

To some extent, the PCIs can basically reflect the distribution of the volcanic ash cloud. In order to more clearly highlight the volcanic ash cloud information in the practical applications, a further detection of the volcanic ash cloud from PCIs is necessary. The specific process is as follows:

- Noise elimination of volcanic ash cloud. In some cases, there are some minor noises in PCIs. In order to overcome the problem, the $3 \times 3$ filter processing is used to process the three obtained PCIs, respectively. Studies show that when the covering area of the multispectral remote sensing data is large enough, the statistics law of each band and its linear processing results in multispectral data basically present the normal distribution (Moghtaderi et al. 2007). 
- False color synthesis. In order to display the volcanic ash cloud information more clearly, in this study, the obtained PCIs which are processed by noise elimination were given red $(\mathrm{R})$, green $(\mathrm{G})$, and blue $(B)$ colors, respectively, and synthesized.

- Color density division. According to the multivariate statistical analysis method, the density division can get the best effect when the divided rule is that the mean value of false color synthesis PCIs plus $n$ times of the standard deviation. Combined with previous research experience and many experiments, it is the ideal way to divide the density into three classes in this study, and the three class rules are 2.0, 2.5, and 3.0 times of the standard deviation. The detected volcanic ash cloud information on 15 and 19 April 2010 is shown in Fig. 7.

Figure 7 shows that the volcanic ash cloud on 19 April 2010 mainly spread towards the south, and then it spread towards the east under the action of gravity and wind. For Class 1, 2, and 3, the concentration of volcanic ash cloud composition within Class 1 region is the greatest; followed by Class 2 region, where the concentration is mediate; the concentration of volcanic ash cloud composition in Class 3 region is the thinnest. In addition, from the distribution point of volcanic ash cloud information, Class 3 is the most widely distributed one in the three classes of volcanic ash cloud region, it is followed by Class 2; and Class 1, which has the smallest distribution area. Furthermore, Class 1 distributes around the center of volcanic ash cloud; with the decrease of volcanic ash cloud concentration, Class 2 mainly locates around the Class 1, and the Class 3 distributes the peripheral region of volcanic ash cloud. In view of this, the usage of the PCA method yields a better

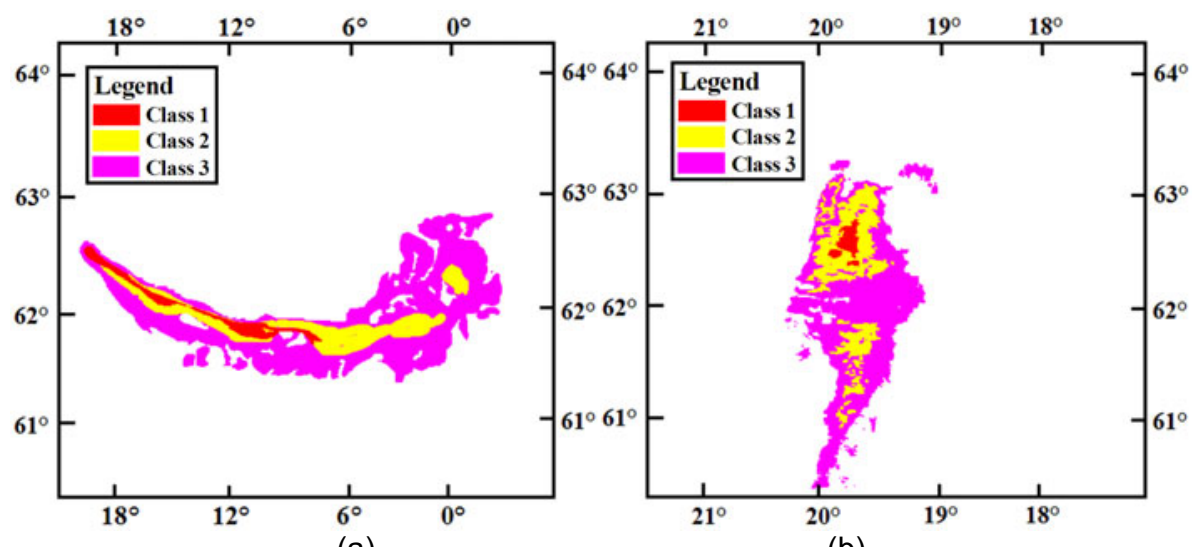

(a)

(b)

Fig. 7. Detected volcanic ash cloud of Eyjafjallajokull volcano: (a) 15 April 2010, and (b) 19 April 2010. 
detecting effect. This method is able to detect not only the shape characteristics of the volcanic ash cloud information but also the different concentration distribution of volcanic ash cloud components. And what is more, the contrast between the obtained volcanic ash cloud and PCIs background characteristics in PCIs is obvious.

\section{MONITORING RESULTS}

In order to verify the detecting effects using PCA method, a comparative analysis was performed in this study on the spectral matching of volcanic ash cloud and volcanic absorbing aerosol index (AAI).

\subsection{Spectral matching of volcanic ash cloud}

In this study, the mineral spectral information of the United States Geological Survey (USGS) standard spectral database is adopted. According to the wavelength interval of MODIS data, the reflectance data in the USGS standard spectral database has been resampled to correspond to MODIS bands, and its spectral curve is established corresponding to MODIS data. Similarity matching between the spectral curve after the atmospheric correction and the standard spectral library of mineral ash after resampling is shown in Fig. 8 .

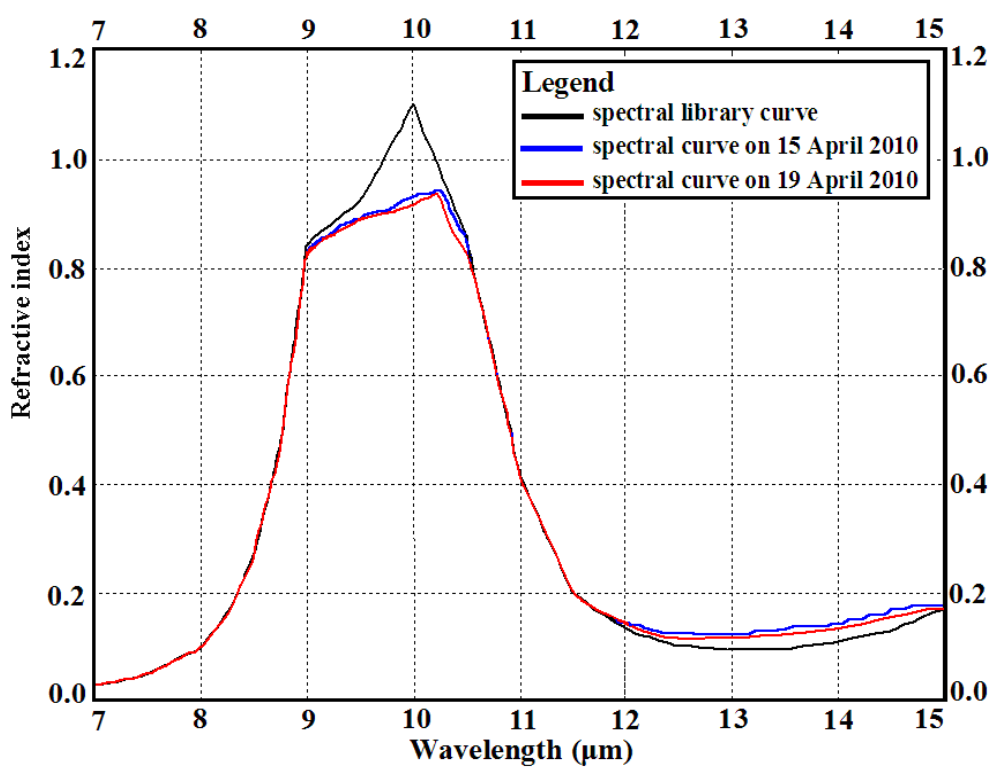

Fig. 8. The spectral curve matching rate of Eyjafjallajokull volcanic ash cloud on 15 and 19 April 2010. 
As can be seen from Fig. 8, the matching rate between the spectral curve and spectral library of volcanic ash cloud reached $74.65 \%$ on 19 April 2010 and $76.35 \%$ on 15 April 2010 , respectively. It shows that the volcanic ash cloud detection using PCA method has achieved good results. In addition, there are some significant differences within a certain wavelength area, such as $9-11 \mu \mathrm{m}$. Based on the analysis, it follows that the main cause is the absorption spectrum differences of thermal infrared bands in these wavelength ranges. And what is more, this is also consistent with the selecting basis of bands 30,31 , and 36 in this study.

Although the actual situation nearby the Eyjafjallajokull volcano, for example the snow-covered surface, ocean surrounding, atmospheric attenuation and terrain differences, reduces the detection precision of the volcanic ash cloud to some extent, the PCA method can still separate out the different object feature information from the mixed information in original remote sensing images based on decorrelation and elimination redundancy. Therefore, the PCA method contributes to detect volcanic ash cloud from the remote sensing image, and makes the detected volcanic ash cloud information closer to the actual distribution.

\subsection{Volcanic AAI}

The volcanic AAI is applied in this study, and it is calculated by the absorbing characteristics of volcanic ash cloud in ultraviolet bands. The AAI on 15 and 19 April 2010 is acquired by the 0.34 and $0.38 \mu \mathrm{m}$ data of the global ozone monitoring experiment (GOME-2) sensor carried on the Metop-A satellite, and shown in Fig. 9.

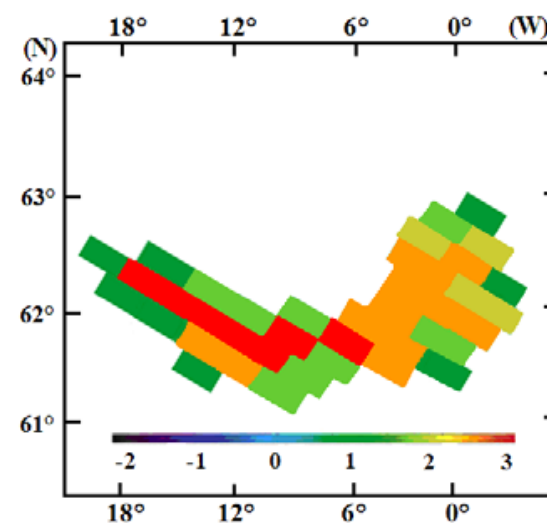

(a)

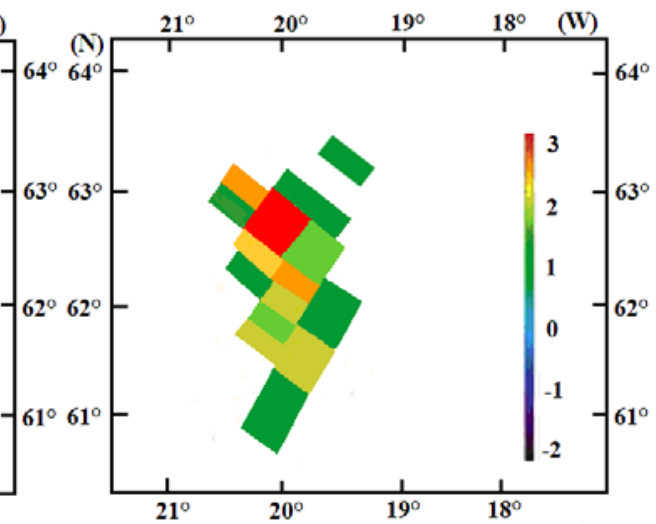

(b)

Fig. 9. The AAI of Eyjafjallajokull volcanic ash cloud: (a) 15 April 2010, and (b) 19 April 2010. 
Figure 9 shows that the maximum concentration position of volcanic AAI basically appears near the volcano and is close to the centric line of volcanic ash cloud. In this paper, the distribution of volcanic ash cloud image on 15 and 19 April 2010 obtained by PCA method is similar to the AAI distribution; it accurately reflects not only the main part of the volcanic ash cloud distribution, but also a small amount of volcanic ash cloud distribution. Due to the lack of the ground measured data of the corresponding region, the volcanic ash cloud acquired by MODIS sensor is used to compare with that of volcanic AAI distributions. The results show that the proposed PCA method can get good monitoring effect of the volcanic ash cloud, and the monitored results have a high consistency and fitness with the volcanic AAI distribution.

\section{CONCLUSIONS AND DISCUSSIONS}

The PCA method not only removes the inter-band correlation and eliminates the data redundancy among the different remote sensing images, but also highlights the characteristics of different objects and improves the detection accuracy of thematic information. In this paper, the PCA method is used to detect the Eyjafjallajokull volcanic ash cloud from MODIS images on 15 and 19 April 2010. Thereinto, the volcanic ash cloud has been detected with the aid of selection of effective spectral bands, PCA processing, noise elimination, and segmentation. And then, the spectral matching rate and volcanic AAI have been adopted to assess the detected volcanic ash cloud. The results show that PCA method has good effect in the detection of volcanic ash cloud, whose spectral matching rate of volcanic ash spectral reaches 74.65 and $76.35 \%$, respectively, and has high consistency with AAI distribution. The PCA method, which is used to detect the volcanic ash cloud from MODIS remote sensing images, has a certain theoretical significance and better practical values for volcanic activity monitoring and aviation safety. In comparison with other research methods (Hillger and Clark 2002a, b, Zhu et al. 2011), the PCA method is much simpler and has a certain detection precision.

Because different types of volcanic eruptions have different volcanic ash cloud components, the formed absorption spectrum characteristics are not exactly the same either. Although PCA method has a huge advantage in the field of volcanic ash cloud detection, it is necessary to select the suitable remote sensing data and wavebands in terms of the actual situation of study area and volcanic eruptions. In addition, compared to PCA method, independent component analysis (ICA) method has some more obvious advantages in the field of remote sensing data processing and volcanic activity monitoring ( $\mathrm{Qu}$ et al. 2006, Li et al. 2013). It can not only remove the inter-band correlation among the different bands of remote sensing data, but also get mutually independent components, which has significant applications in vol- 
canic ash cloud detection. However, the related researches are rarely involved, and this needs to be further discussed.

Acknowledgments. We thank the vital comments and suggestions made by the anonymous reviewers and editorial team. This work was co-supported by the Projects of National Science Foundation of China (41404024), Laboratory Technician Team Building Program in Shanghai Universities (B.60-E108-14-101), Young Teachers Training and Supporting Plan in Shanghai Universities (2014-2016), and Shanghai University Innovation Fund (2014-2016).

\section{References}

Andronico, D., C. Spinetti, A. Cristaldi, and M.F. Buongiorno (2009), Observations of Mt. Etna volcanic ash plumes in 2006: An integrated approach from ground-based and polar satellite NOAA-AVHRR monitoring system, J. Volcanol. Geoth. Res. 180, 2-4, 135-147, DOI: 10.1016/j.jvolgeores. 2008.11.013.

Ellrod, G.P. (2004), Impact on volcanic ash detection caused by the loss of the $12.0 \mu \mathrm{m}$ "Split Window" band on GOES imagers, J. Volcanol. Geoth. Res. 135, 1-2, 91-103, DOI: 10.1016/j.jvolgeores.2003.12.009.

Filizzola, C., T. Lacava, F. Marchese, N. Pergola, I. Scaffidi, and V. Tramutoli (2007), Assessing RAT (Robust AVHRR Techniques) performances for volcanic ash cloud detection and monitoring in near real-time: the 2002 eruption of Mt. Etna (Italy), Remote Sens. Environ. 107, 3, 440-454, DOI: 10.1016/j.rse.2006.09.020.

Flynn, L.P., A.J.L. Harris, and R. Wright (2001), Improved identification of volcanic features using Landsat 7 ETM+, Remote Sens. Environ. 78, 1-2, 180-193, DOI: $10.1016 / \mathrm{S} 0034-4257(01) 00258-9$.

Hillger, D.W., and J.D. Clark (2002a), Principal component image analysis of MODIS for volcanic ash. Part 1: Most important bands and implications for future GOES imagers, J. Appl. Meteor. 41, 10, 985-1001, DOI: 10.1175/ 1520-0450(2002)041<0985:PCIAOM>2.0.CO;2.

Hillger, D.W., and J.D. Clark (2002b), Principal component image analysis of MODIS for volcanic ash. Part II: Simulation of current GOES and GOESM imagers, J. Appl. Meteor. 41, 10, 1003-1010, DOI: 10.1175/1520-0450 (2002)041<1003:PCIAOM>2.0.CO;2.

Hillger, D.W., and G.P. Ellrod (2003), Detection of important atmospheric and surface features by employing principal component image transformation of 
GOES imagery, J. Appl. Meteor. 42, 5, 611-629, DOI: 10.1175/1520-0450 (2003)042<0611:DOIAAS $>2.0 . C O ; 2$.

Jiménez-Muñoz, J.C., and J.A. Sobrino (2003), A generalized single-channel method for retrieving land surface temperature from remote sensing data, J. Geophys. Res. 108, D22, 4688-4695, DOI: 10.1029/2003JD003480.

Krueger, A.J. (1983), Sighting of El Chichón sulfur dioxide clouds with the Nimbus 7 total ozone mapping spectrometer, Science 220, 4604, 1377-1379, DOI: 10.1126/science.220.4604.1377.

Li, C.F., J.Y. Yin, J.S. Dong, and D. Shen (2013), Monitoring of volcanic ash cloud based on thermal infrared satellite remote sensing, Infrared Technol. 35, 8, 487-491.

Li, J., Z.G. Han, H.B. Chen, Z.L. Zhao, and H.Y. Wu (2011), Detection of heavy fog events over North China Plain by using the geostationary satellite data, Remote Sens. Technol. Appl. 26, 2, 186-195 (in Chinese).

Lin, C., F. Peng, B.H. Wang, W.F. Sun, and X.J. Kong (2012), Research on PCA and KPCA self-fusion based MSTAR SAR automatic target recognition algorithm, J. Electron. Sci. Technol. 10, 4, 352-357.

Liu, Z.W., A,R. Dang, Z.D. Lei, and Y.G. Huang (2003), A retrieval model of land surface temperature with ASTER data and its application study, Progr. Geogr. 22, 5, 507-514 (in Chinese).

Mastin, L.G., M. Guffanti, R. Servranckx, P. Webley, S. Barsotti, K. Dean, A. Durant, J.W. Ewert, A. Neri, W.I. Rose, D. Schneider, L. Siebert, B. Stunder, G. Swanson, A. Tupper, A. Volentik, and C.F. Waythomas (2009), A multidisciplinary effort to assign realistic source parameters to models of volcanic ash-cloud transport and dispersion during eruptions, J. Volcanol. Geoth. Res. 186, 1-2, 10-21, DOI: 10.1016/j.jvolgeores.2009.01.008.

McCarthy, E.B., G.J.S. Bluth, I.M. Watson, and A. Tupper (2008), Detection and analysis of the volcanic clouds associated with the 18 and 28 August 2000 eruptions of Miyakejima volcano, Japan, Int. J. Remote Sens. 29, 22, 65976620, DOI: 10.1080/01431160802168400.

Moghtaderi, A., F. Moore, and A. Mohammadzadeh (2007), The application of advanced space-borne thermal emission and reflection (ASTER) radiometer data in the detection of alteration in the Chadormalu paleocrater, Bafq region, Central Iran, J. Asian Earth Sci. 30, 2, 238-252, DOI: 10.1016/ j.jseaes.2006.09.004.

Qin, Z.H., A. Karnieli, and P. Berliner (2001), A mono-window algorithm for retrieving land surface temperature from Landsat TM data and its application to the Israel-Egypt border region, Int. J. Remote Sens. 22, 18, 3719-3746, DOI: $10.1080 / 01431160010006971$. 
Qu, C.Y., X.J. Shan, and J. Ma (2006), Application of satellite thermal infrared remote sensing in detection of volcano activity, Seismol. Geol. 28, 1, 99-110.

Rose, W.I., S. Self, P.J. Murrow, C. Bonadonna, A.J. Durant, and G.G.J. Ernst (2008), Nature and significance of small volume fall deposits at composite volcanoes: Insights from the October 14, 1974 Fuego eruption, Guatemala, Bull. Volcanol. 70, 9, 1043-1067, DOI: 10.1007/s00445-007-0187-5.

Thomas, W., T. Erbertseder, T. Ruppert, M. van Roozendael, J. Verdebout, D. Balis, C. Meleti, and C. Zerefos (2005), On the retrieval of volcanic sulfur dioxide emissions from GOME backscatter measurements, J. Atmos. Chem. 50, 3, 295-320, DOI: 10.1007/s10874-005-5544-1.

Webley, P., and L. Mastin (2009), Improved prediction and tracking of volcanic ash clouds, J. Volcanol. Geoth. Res. 186, 1-2, 1-9, DOI: 10.1016/j.jvolgeores. 2008.10.022.

Wen, S.M., and W.I. Rose (1994), Retrieval of sizes and total masses of particles in volcanic clouds using AVHRR bands 4 and 5, J. Geophys. Res. 99, D3, 5421-5431, DOI: 10.1029/93JD03340.

Yao, Y.J., P. Nan, Z.L. Zhang, and B.S. Li (2007), Application of split window algorithm in land surface temperature retrieval from thermal infrared remote sensing data, J. Lanzhou Univ. Technol. 33, 6, 89-92 (in Chinese).

Zhao, Q., Z.L. Xie, H. Li, and X.L. Li (2012), Color-feature extraction of remote sensing image based on principal components analysis and K-means, $M i$ croelectron. Comput. 29, 10, 61-68 (in Chinese).

Zhu, L., J. Liu, C. Liu, and M. Wang (2011), Satellite remote sensing of volcanic ash cloud in complicated meteorological conditions, Sci. China Earth Sci. 54, 11, 1789-1795, DOI: 10.1007/s11430-011-4265-3. 